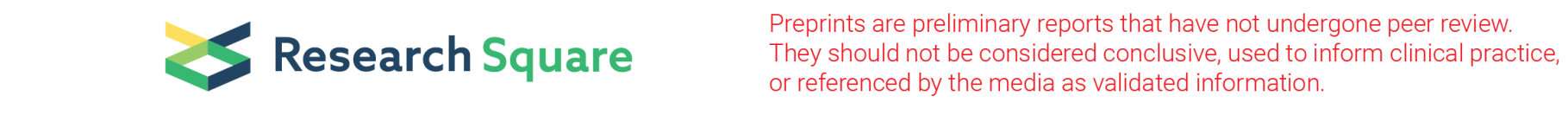

\title{
Prevalence and antimicrobial resistance of animal Salmonellosis in Ethiopia
}

\section{Atsebaha Gebrekidan Kahsay ( $\sim$ atsebahagebrekidan226@gmail.com )}

\section{Research article}

Keywords: animal salmonellosis, antimicrobial resistance, serotype, Ethiopia

Posted Date: March 10th, 2020

DOl: https://doi.org/10.21203/rs.3.rs-16482/v1

License: (c) (1) This work is licensed under a Creative Commons Attribution 4.0 International License. Read Full License 


\section{Abstract}

Background Salmonellosis remained the global public health problems of animals and humans. Consumption of animal food from infected animals or from the contamination of carcasses such as cattle, swine, and sheep and poultry are the main sources of non-Typhoidal Salmonella and the leading cause of zoonotic foodborne diseases. The eligibility criteria of this study has included publication in English, cross-sectional study, samples of food animal origin, antimicrobial sensitivity test methods. Google Scholar and PubMed have used to search the prevalence, incidence, distribution, antimicrobial resistance, animals and humans. Author, study area, study period, sample sources, number of animals, number of samples, positive isolates were used as search strategy.

Results A total of 8.4\% (564/6721) animal salmonellosis were identified from 11 studies in Ethiopia. The source of samples were pigs, cattle, poultry, and eggs. Five studies were selected for the analysis of prevalence and drug resistance of animal salmonellosis whereas six were found eligible for analysis of animal salmonellosis in serotype level and twenty nine serotypes were extracted having 354 isolates. Of the total $147(6.1 \%)$ isolates in five studies, ampicillin, streptomycin and tetracycline were resistant to 89 (60.5\%), 70 (47.6\%) and 64(43.5\%) respectively. The resistant profile for ceftriaxone, gentamicin and ciprofloxacin were 20 (13.6\%), 21 (12.9\%) and 10 (6.8\%), respectively. Twelve serotypes having 204 isolates have showed antimicrobial resistance. Six serotypes had multidrug resistance comprising 120 isolates. The predominant serotype that showed MDR (to three antibiotics) was S. Hadar 81 (67.5\%) followed by S. Kentucky 22(18.3\%).

Conclusion The overall prevalence of animal salmonellosis in Ethiopia was 8.4\% (564/6721). The source of samples for the assessment of the prevalence of animal salmonellosis in Ethiopia were pigs, cattle, poultry, and eggs. Of the total 147(6.1\%) isolates in five studies, ampicillin, streptomycin and tetracycline were resistant to 89 (60.5\%), 70 (47.6\%) and 64(43.5\%), respectively. A total of 29 serotypes comprising 354 isolates were revealed from six studies. Twelve serotypes having 204 isolates were showed antimicrobial resistance. Six serotypes showed multidrug resistance and the predominant serotype that showed MDR was S. Hadar 81 (67.5\%) followed by S. Kentucky 22(18.3\%)

\section{Background}

\section{Overview of Salmonellosis}

Salmonellae seems to be familiarized in the digestive system of humans and animals. Hence, the presence of Salmonellae in water, food, and environment is elucidated by fecal contamination (1). More than 2500 serotypes/serovars of Salmonellae has been reported (2) and of which 1500 subspecies are associated with human and animal diseases (3) although there is a variation in nature and rigidity among different animals and affected by age, dose, strain virulence, host species, immune status of the host and geographic regions (4). The most clinically important species of Salmonellae is Salmonella enterica subspecies enterica (2). Salmonella enterica subspecies enterica serotype Typhi and para Typhi are highly adapted to human and causes Typhoid fever and para Typhoid fever (5) whereas there are serotypes of Salmonella that adapted animals such as S. Choleraesuis in pigs, S. Dublin in cattle, S. Abortusovis in sheep and S. Gallinarum in poultry; however, some serotypes like S. Typhimurium affect human and a wide range of animals (6). Consumption of raw/undercooked meat, raw/undercooked eggs and not cleaning chopping board when using it for raw meat and other foods are the contributing factors for the transmission of human Salmonellosis (7).

Nontyphoidal Salmonella cause bacteremia in the globe particularly in Africa and the annual burden is estimated to be 3.4 million (8) even though the majority of human NTS infection in developed countries are associated with enterocolitis and this is believed to arise through the food chain (9). Non-Typhoidal Salmonella is the leading cause of zoonotic foodborne diseases that are linked with the consumption of infected animals used in food production or from contamination of the carcasses (10) such as cattle, swine, and sheep (11). Animals are the main reservoirs of human Salmonellosis $(12,13)$ though vegetable foods contaminated by animal products and human excreta have been implicated as the automobile of human salmonellosis (14). Salmonellae in the infected animals' mesenteric lymph nodes and feces can contribute as a 
source for the contamination of red meat and other edible parts of the carcasses $(14,15)$ and also by the contaminated abattoir equipment and utensils $(15,16)$.

The public health problem of Salmonella is not only by its infection but also by its drug resistance and economic impacts (17). The highest number of illnesses, hospitalizations, and deaths associated with foodborne illness are due to nonTyphoidal Salmonella (18). About 100,000 infections are associated with drug-resistant Salmonella such as annual infections due to ceftriaxone and ciprofloxacin in the United States of America, are 36,000 and 33,000 respectively (17).

\section{Prevalence of Animal Salmonellosis}

The prevalence of animal Salmonellosis in chicken meat from Vietnam (15), Russia (18), Iran(16), in chicken meat, beef and pork from South Korea (19) and from poultry in China (21) were 128 (48.9\%), 220 (31.5\%), 111(19.8\%), 17 (13\%), 601 (52.2\%), respectively.

Twelve (1.1\%) Salmonella species were isolated from 1,108 meat samples in New Zealand with a proportion of 3\% in chicken, $1.3 \%$ in lamb and mutton, $0.5 \%$ in beef, and $0 \%$ in pork (22) and Salmonella was isolated from $22 \%$ (31 of 141 ) of the conventional and $20.8 \%$ (11 of 53) of the organic chicken samples in Louisiana (23). Of the total 225 retail meat products conducted in Turkey, 50 (22.2\%) were positive for Salmonella with $22(29.3 \%)$ poultry meat $(n=75), 16(21.3 \%)$ ground beef $(n=75)$, and $12(16 \%)$ beef $(n=75)(20 \%)(24)$. Salmonella strains were isolated from $271(27 \%)$ carcass samples in Colombia (25).

Of the examined poultry meat samples in Egypt, 10 (10\%) Salmonella species were isolated (26). Salmonella was isolated from 383 (53\%) of the total of 729 fecal samples including 159 (52\%) of the cattle feces, 192 (55\%) of the chicken feces, 8 $(16 \%)$ of the swine feces and $24(96 \%)$ of the hedgehog feces in Burkinafaso (27). Of the 435 retailed beef and related meat products tested in a study conducted in Nigeria, 10 (2.3\%) Salmonella species isolates were revealed (28).

A total 624 and 600 samples examined from sheep and goats in Ethiopia and 18 (2.9\%) and 4 (0.7\%) were Salmonella positive (29), respectively and of the 156 chicken eggs examined in another study in Ethiopia, 24 (15.4\%) for eggshells and $13(8.3 \%)$ for yolks were found positive for Salmonellosis (30). Two (1.3\%) of the 150 carcasses were found contaminated with Salmonella species in Ethiopia (31). From the 300 meat samples examined, 44(14.7\%) were positive for Salmonella including $14.4 \%$ (23/160) minced beef, 14.1\% (12/85) mutton and 16.4\% (9/55) pork samples (32). Salmonellae were isolated from 45 of the 270 samples (16.67\%) carried out in Ethiopia (33).

\section{Serotypes and Antimicrobial Resistance of animal Salmonellosis}

The most common serotypes identified in Vietnam were S. Agona, S. Emek, and S. London. The identification rates of S. Enteritidis and S. Typhimurium were few (15). The predominant serotypes revealed in a study carried out in South Korea were Salmonella enterica Panama (beef), and Salmonella London and Salmonella Montevideo (chicken meat and pork). All of the isolates of Salmonella species were showed resistance to erythromycin whereas $22.2 \%$ for streptomycin and $16.7 \%$ for tetracycline and chloramphenicol (24). Five Serotypes of Salmonella including S. Thompson, S. Typhimurium, S. Newport, and S. Hadar were isolated from the chicken meat in Iran. High antimicrobial resistance rates were observed to nalidixic acid (92.8\%), tetracycline (81\%), streptomycin (56.7\%), and kanamycin (36.9\%) (16). Eight Salmonella serovars were identified in Louisiana with the predominant serovars of Kentucky, Hadar, and Enteritidis (23) whereas S. Typhimurium was the predominant serovars in Turkey (24).

S. Typhimurium, S. Rubislaw, S. Kiel and S. Derby were the serovars identified in Egypt and were found resistance to ampicillin (57.1\%), streptomycin (71.4\%), tetracycline (100\%), ciprofloxacin (28.6\%), chloramphenicol (85.7\%) and gentamycin (71.4\%) (26).

Different serovars were identified from different areas of Ethiopia. S. Typhimurium, S. Heidelberg, S. reading, S. give, and S. Poona were reported from central Ethiopia (29), S. Muenchen, S. Korovi and S. 1, 4, 5, 12, i :- from Hawassa (30) whereas S. 
Infantis, S. Braenderup, S. Anatum, and S. Bovismorbificans, S. Vejle, S. Dublin, S. Saintpaul, S. I: 8:20:- and S. I: 47:z4:z23 from Addis Ababa (32). All of the 45 isolates of Salmonella described in Southern Ethiopia (100\%) were resistant to kanamycin and sulfamethoxazole-trimethoprim. Almost all (97.8\%) isolates had resistance to ampicillin, nalidixic acid, streptomycin, and tetracycline. Resistance to chloramphenicol and ciprofloxacin was $91.1 \%$ and $31.1 \%$, respectively (33).

\section{Results}

\section{Eligible and exclusion studies}

A total of 222 published articles were searched. Of these, 205 articles were excluded after reviewing their abstracts. The remaining 17 articles have assessed their full text and 3 were excluded due to failure to include antimicrobial susceptibility testing $(31-33)$.

Eleven articles were included in the study. Six of them were eligible to estimate the prevalence of animal salmonellosis and their antimicrobial resistance whereas the remaining five were eligible for serotype and antimicrobial resistance analysis. The selection of eligible studies were based on PRISMA 2009 (35) as illustrated in Fig. 1.

\section{Characteristics of the eligible studies of animal salmonellosis}

The characteristics of the eligible studies presented in Table 1. The studies were conducted between 2004 and 2018. Except for two (one from Bahir Dar and one from Wolaita Sodo) studies, all of the eligible studies were carried out in Addis Ababa and Oromia. Seven of the eleven eligible studies were cattle and the majority of the samples collected were fecal materials, caecal content and mesenteric lymph nodes. All of the eligible studies used international organization for standardization (ISO) during isolation, identification, and characterization of salmonella species. Ten of the eligible studies had used buffered peptone water for sample collection as enrichment and all of them were used xylose lysine deoxycholate (XLD) agar for the isolation of Salmonella. Parallel to XLD, brilliant green (BGA) agar in five studies and brilliant green phenol red lactose sucrose (BPLS) agar in three studies were used for the isolation of Salmonella. 
Table 1

Characteristics of the eligible studies of animal salmonellosis in Ethiopia.

\begin{tabular}{|c|c|c|c|c|c|c|c|c|c|}
\hline Author & Location & $\begin{array}{l}\text { Study } \\
\text { period }\end{array}$ & Animal & $\begin{array}{l}\text { Sample } \\
\text { sources }\end{array}$ & $\begin{array}{l}\text { Isolation } \\
\text { Method }\end{array}$ & $\begin{array}{l}\text { Samples } \\
\text { number }\end{array}$ & Isolates & $\begin{array}{l}\text { Number } \\
\text { of drugs }\end{array}$ & $\begin{array}{l}\text { Drug } \\
\text { test }\end{array}$ \\
\hline (36) & $\begin{array}{l}\text { Addis } \\
\text { Ababa }\end{array}$ & $\begin{array}{l}2004- \\
2005\end{array}$ & Pig & $\begin{array}{l}\mathrm{Cc}, \mathrm{MLN}, \mathrm{L}, \\
\mathrm{T}, \mathrm{Ma}\end{array}$ & ISO & 501 & 94 & 24 & Mic \\
\hline (37) & $\begin{array}{l}\text { Addis } \\
\text { Ababa }\end{array}$ & $\begin{array}{l}2004- \\
2005\end{array}$ & Pig & Cc, MLN & ISO & 833 & 173 & 24 & Mic \\
\hline (38) & Debre Zeit & $\begin{array}{l}2005- \\
2006\end{array}$ & Cattle & $\begin{array}{l}\text { H, R, Cc, } \\
\text { MLN, C }\end{array}$ & ISO & 500 & 66 & 24 & Mic \\
\hline (39) & Bahir Dar & $\begin{array}{l}2006- \\
2007\end{array}$ & Cattle & $\begin{array}{l}\text { LT MLN, IC, } \\
\text { C }\end{array}$ & ISO & 744 & 28 & 8 & Dzi \\
\hline (40) & $\begin{array}{l}\text { Addis } \\
\text { Ababa }\end{array}$ & 2010 & Cow & F, Mil & ISO & 390 & 21 & 11 & Dzi \\
\hline (41) & $\begin{array}{l}\text { Addis } \\
\text { Ababa }\end{array}$ & 2013 & Cattle & $\mathrm{F}$ & ISO & 1203 & 30 & 18 & Dzi \\
\hline (42) & $\begin{array}{l}\text { Wolaita } \\
\text { Sodo }\end{array}$ & $\begin{array}{l}2015- \\
2016\end{array}$ & Cattle & $\mathrm{Ab}, \mathrm{Th}$ & ISO & 896 & 56 & 12 & Dzi \\
\hline (43) & Oromia & $\begin{array}{l}2015- \\
2016\end{array}$ & Cattle & MLN, F & ISO & 300 & 17 & 10 & Dzi \\
\hline (44) & $\begin{array}{l}\text { Addis } \\
\text { Ababa }\end{array}$ & $\begin{array}{l}2013- \\
2014\end{array}$ & Poultry & $\mathrm{F}$ & ISO & 549 & 26 & 18 & Dzi \\
\hline (45) & Jimma & 2016 & Cattle & $\mathrm{Cc}, \mathrm{F}$ & ISO & 390 & 42 & 10 & Dzi \\
\hline \multirow[t]{2}{*}{$(46)$} & Jimma & 2018 & Egg & ESS & ISO & 415 & 11 & 12 & Dzi \\
\hline & & & & & & 6721 & 564 & & \\
\hline $\begin{array}{l}\text { Cc caece } \\
\text { muscle, } \\
\text { thorax, } \\
\text { inhibitio }\end{array}$ & $\begin{array}{l}\text { I content, ML } \\
\text { fecal, } \mathrm{H} \text { hide } \\
\text { h.clo Chicken } \\
\text { concentratic }\end{array}$ & $\begin{array}{l}\text { V Mesent } \\
\text { R rumer } \\
\text { cloacal, } \\
\text { ns, dzi = }\end{array}$ & $\begin{array}{l}\text { Imph no } \\
\text { arcass, L } \\
\text { gg surfa } \\
\text { eter of } z\end{array}$ & $\begin{array}{l}\text { L Liver, T to } \\
\text {-iver tissue, I } \\
\text { swab, ISO = } \\
\text { e of inhibitio }\end{array}$ & $\begin{array}{l}\text { te, Ma mu } \\
\text { testinal } \\
\text { ernational }\end{array}$ & $\begin{array}{l}\text { spleen, D } \\
\text { t, Mil Milk, } \\
\text { nizations f }\end{array}$ & $\begin{array}{l}\text { iaphragm } \\
\text { Meat, Ab } \\
\text { Standard }\end{array}$ & $\begin{array}{l}\text { M abdom } \\
\text { bdominal } \\
\text { mic }=\text { Min }\end{array}$ & um \\
\hline
\end{tabular}

A total of 6721 samples were collected from pig, cattle, poultry, and eggs and 564(8.4\%) Salmonella species were identified. Of the eleven eligible studies, the positivity range of Salmonella was from 30 (2.5\%) in cattle 173 (20.8\%) in Pigs from Addis Ababa. The highest prevalence of Salmonella was observed in pigs 173 (20.8\%) in Addis Ababa followed by pigs 94(18.8\%) in Addis Ababa and cattle 66 (13.2\%) in Debrezeit. Eight (72.7\%) of the eleven studies used the disc diffusion method to test the effect of antimicrobials on the isolated Salmonella and measured the diameter of the zone of inhibition (Dzi), Table 1.

\section{Distribution of Salmonella Serotypes among animals in Ethiopia}

Six studies were eligible for Salmonella serotype analysis and 29 serotypes were summarized. Except for one study from Bahir Dar, all of the eligible studies were carried out in Addis Ababa and Debrezeit, Ethiopia. S. Hadar was the predominant (74/354, 20.9\%) serotype reveal followed by S. Saintpaul (55/354, 15.5\%), S. Anatum (49/354, 13.8\%), S. Eastbourne $(41 / 354,11.6 \%)$, and S. Typhimurium (31/354, 8.8\%), respectively, Table 2. 
Table 2

Distribution of Salmonella Serotypes among animals in Ethiopia, 2004-2014

\begin{tabular}{|c|c|c|c|c|c|c|c|c|}
\hline \multirow[t]{2}{*}{ Identified Serotype } & \multicolumn{6}{|c|}{ References, n (\%) } & \multirow{2}{*}{$\begin{array}{l}\text { Total } \\
(\%)\end{array}$} & \multirow[t]{2}{*}{ Infected animals } \\
\hline & (36) & (37) & (38) & (39) & (41) & (44) & & \\
\hline S. Hadar & 38 & 36 & - & - & - & - & $\begin{array}{l}74 \\
(20.9)\end{array}$ & Pig, pig \\
\hline S. Saintpaul & & 29 & - & - & 6 & 20 & $\begin{array}{l}55 \\
(15.5)\end{array}$ & Pig, cattle, poultry \\
\hline S. Anatum & 8 & 2 & 39 & - & - & - & $\begin{array}{l}49 \\
(13.8)\end{array}$ & Pig, Pig, cattle \\
\hline S. Eastbourne & 1 & 32 & 8 & - & - & - & $\begin{array}{l}41 \\
(11.6)\end{array}$ & Pig, Pig, cattle \\
\hline S. Typhimurium & & 14 & 1 & 6 & 7 & 3 & $\begin{array}{l}31 \\
(8.8)\end{array}$ & $\begin{array}{l}\text { Pig, pig, cattle, cattle, cattle, } \\
\text { poultry }\end{array}$ \\
\hline S. Kentucky & 15 & 3 & - & - & 5 & 2 & $\begin{array}{l}25 \\
(7.1)\end{array}$ & Pig, cattle, poultry \\
\hline S. Newport & 1 & 4 & 13 & 6 & - & - & $\begin{array}{l}24 \\
(6.8)\end{array}$ & Pig, cattle, cattle \\
\hline S. Enteritidis & 5 & 4 & - & - & - & - & $9(2.5)$ & Pig \\
\hline S. Infantis & & 2 & - & 5 & - & - & $7(2)$ & Pig, cattle \\
\hline S. Virchow & & - & - & - & 5 & - & $5(1.4)$ & Cattle \\
\hline S. Haifa & & - & - & 3 & - & 1 & $4(1.1)$ & Cattle \\
\hline S. Havana & 3 & 1 & - & - & - & - & $4(1.1)$ & Pig \\
\hline S. Dublin & & - & - & - & 3 & - & $3(0.8)$ & Cattle \\
\hline S. Amager & & 2 & - & - & - & - & $\begin{array}{l}2 \\
(0.56)\end{array}$ & Pig \\
\hline S. Kottbus & & 2 & - & - & - & - & $2(0.56)$ & Pig \\
\hline S. II 40:b:- & & - & 2 & - & - & - & $2(0.56)$ & Cattle \\
\hline S. Muenchen & & 2 & - & - & - & - & $2(0.56)$ & Pig \\
\hline S. Heidelberg & & - & - & 2 & - & - & $2(0.56)$ & Cattle \\
\hline $\begin{array}{l}\text { S. } \\
\text { Mishmarhaemek }\end{array}$ & & - & - & 2 & - & - & $2(0.56)$ & Cattle \\
\hline S. Uganda & 1 & - & 1 & - & - & - & $2(0.56)$ & Cattle \\
\hline S. Braenderup & & 1 & - & - & - & - & $\begin{array}{l}1 \\
(0.28)\end{array}$ & Pig \\
\hline S. Meleagridis & & 1 & - & - & - & - & $\begin{array}{l}1 \\
(0.28)\end{array}$ & Pig \\
\hline S. Tarshyne & & 1 & - & - & - & - & $\begin{array}{l}1 \\
(0.28)\end{array}$ & Pig \\
\hline S. Bredeney & & - & 1 & - & - & - & $\begin{array}{l}1 \\
(0.28)\end{array}$ & Cattle \\
\hline
\end{tabular}




\begin{tabular}{|c|c|c|c|c|c|c|c|c|}
\hline \multirow[t]{2}{*}{ Identified Serotype } & \multicolumn{6}{|c|}{ References, n (\%) } & \multirow{2}{*}{$\begin{array}{l}\text { Total } \\
\text { (\%) }\end{array}$} & \multirow[t]{2}{*}{ Infected animals } \\
\hline & (36) & (37) & (38) & (39) & (41) & (44) & & \\
\hline S. Urbana & & - & 1 & - & - & - & $\begin{array}{l}1 \\
(0.28)\end{array}$ & Cattle \\
\hline S. Aberdeen & & - & - & - & 1 & - & $\begin{array}{l}1 \\
(0.28)\end{array}$ & Cattle \\
\hline S. I:6,7,14:-: I,W & & - & - & - & 1 & - & $\begin{array}{l}1 \\
(0.28)\end{array}$ & Cattle \\
\hline $\begin{array}{l}\text { S. } \\
\text { LivingstoneVar.14+ }\end{array}$ & & - & - & - & 1 & - & $\begin{array}{l}1 \\
(0.28)\end{array}$ & Cattle \\
\hline S. Mikawasima & & - & - & - & 1 & - & $\begin{array}{l}1 \\
(0.28)\end{array}$ & Cattle \\
\hline $\begin{array}{l}\text { Total (29 } \\
\text { serotypes) }\end{array}$ & $\begin{array}{l}72 \\
(20.3)\end{array}$ & $\begin{array}{l}136 \\
(38.4)\end{array}$ & $66(18.6)$ & $\begin{array}{l}24 \\
(6.8)\end{array}$ & $\begin{array}{l}30 \\
(8.5)\end{array}$ & $\begin{array}{l}26 \\
(7.3)\end{array}$ & $\begin{array}{l}354 \\
(100)\end{array}$ & \\
\hline
\end{tabular}

\section{Prevalence and Antimicrobial Resistance of Animal Salmonellosis in Ethiopia}

In two of the eligible studies, all of the isolates showed $100 \%$ resistance to ampicillin $(40,43)$ and about $7 \%(n=4)$ and $35 \%$ $(n=6)$ of isolates in two studies revealed resistance to ciprofloxacin $(42,43)$. Of the five eligible studies analyzed, resistance for ceftriaxone was recorded in two studies $(42,46)$. A total of 2391 samples were reviewed from the five eligible studies and 147 (6.1\%) Salmonella species were summarized, Table 3

Table 3

Prevalence and Antimicrobial Resistance of Animal Salmonellosis in Ethiopia

\begin{tabular}{|c|c|c|c|c|c|c|c|c|c|c|}
\hline \multirow[t]{2}{*}{ References } & \multirow{2}{*}{$\begin{array}{l}\text { Number } \\
\text { of } \\
\text { Samples }\end{array}$} & \multirow{2}{*}{$\begin{array}{l}\text { Positive } \\
\text { Isolates }\end{array}$} & \multicolumn{8}{|c|}{ Antimicrobial resistance (\%) } \\
\hline & & & AMP & GEN & CIP & C & $S$ & $\mathrm{~T}$ & $F$ & CRO \\
\hline$(40)$ & 390 & $21(5.4)$ & $21(100)$ & $4(19)$ & $0(0)$ & $\begin{array}{l}2 \\
(9.5)\end{array}$ & $\begin{array}{l}16 \\
(76.2)\end{array}$ & $7(33.3)$ & $\begin{array}{l}13 \\
(61.9)\end{array}$ & $\mathrm{Nt}$ \\
\hline$(42)$ & 896 & $56(6.3)$ & $\begin{array}{l}26 \\
(46.4)\end{array}$ & $\begin{array}{l}7 \\
(12.5)\end{array}$ & $4(7.1)$ & $\begin{array}{l}29 \\
(51.8)\end{array}$ & $\begin{array}{l}37 \\
(66.1)\end{array}$ & $\begin{array}{l}47 \\
(83.9)\end{array}$ & $\begin{array}{l}41 \\
(73.2)\end{array}$ & $\begin{array}{l}13 \\
(23.2)\end{array}$ \\
\hline (43) & 300 & $17(5.7)$ & $17(100)$ & $\begin{array}{l}5 \\
(29.4)\end{array}$ & $\begin{array}{l}6 \\
(35.3)\end{array}$ & $0(0)$ & $7(41.1)$ & $\mathrm{Nt}$ & $5(29.4)$ & $0(0)$ \\
\hline (45) & 390 & $\begin{array}{l}42 \\
(10.8)\end{array}$ & $13(31)$ & $\begin{array}{l}3 \\
(7.1)\end{array}$ & $0(0)$ & $\begin{array}{l}3 \\
(7.1)\end{array}$ & $\begin{array}{l}10 \\
(23.8)\end{array}$ & $\begin{array}{l}10 \\
(23.8)\end{array}$ & $\mathrm{Nt}$ & $0(0)$ \\
\hline$(46)$ & 415 & $11(2.7)$ & $\begin{array}{l}10 \\
(90.9)\end{array}$ & $0(0)$ & $0(0)$ & $0(0)$ & $0(0)$ & $0(0)$ & $0(0)$ & $\begin{array}{l}7 \\
(63.6)\end{array}$ \\
\hline Total & 2391 & $\begin{array}{l}147 \\
(6.1)\end{array}$ & $87(59.2)$ & $\begin{array}{l}19 \\
(12.9)\end{array}$ & $10(6.8)$ & $\begin{array}{l}34 \\
(23.1)\end{array}$ & $70(47.6)$ & $64(43.5)$ & $59(40.1)$ & $\begin{array}{l}20 \\
(13.6)\end{array}$ \\
\hline
\end{tabular}

Of the total $147(6.1 \%)$ Salmonella species summarized, $89(60.5 \%), 70(47.6 \%)$ and $64(43.5 \%)$ isolates were found resistant for ampicillin, streptomycin, and tetracycline, respectively. The antibiotics that showed less resistance were ciprofloxacin 10 (6.8\%), gentamicin 21 (12.9\%) and ceftriaxone 20 (13.6\%), respectively, Fig. 2. 


\section{Salmonella Serotype and their antimicrobial resistance in animals}

Six studies were included to assess the antimicrobial resistance of serotypes of animal salmonellosis. In each of the eligible studies, top isolates of 12 serotypes comprising 204 isolates were selected to check their resistance status. Accordingly, of the 47 serovars of S. Hadar, $97.9 \%$ were resistant to streptomycin and tetracycline (37). Two (22.2\%) of the nine tested S. Typhimurium showed resistance to ampicillin, ciprofloxacin, chloramphenicol, streptomycin, and tetracycline (37) and similarly, one of the six (16.7\%) tested S. Typhimurium was found resistant to chloramphenicol, streptomycin, and tetracycline (39). In another study, three S. Typhimurium was tested and all of them were resistant to streptomycin and one (33.3\%) to tetracycline (41) although no resistance was observed for the seven, tested S, Typhimurium in a study carried out by Eguale (44).

All of the isolates $(n=5)$ of S. Kentucky showed resistance for ampicillin and ciprofloxacin but $80 \%(n=4)$ for streptomycin and tetracycline (37). Similarly, five isolates of S. Kentucky in a study carried out by Eguale (41) and two isolates of S. Kentucky in another study by Eguale (44) were tested and all of them were resistance for ampicillin, gentamycin, ciprofloxacin, streptomycin and tetracycline, Table 4. 
Table 4

Salmonella Serotype and antimicrobial resistance in animals in Ethiopia

\begin{tabular}{|c|c|c|c|c|c|c|c|c|}
\hline \multirow[t]{2}{*}{ Author } & \multirow[t]{2}{*}{ S. Serotypes tested } & \multicolumn{7}{|c|}{ Antimicrobial Resistance (\%) } \\
\hline & & AMP & GEN & CIP & C & $\mathbf{s}$ & $T$ & $\mathrm{~F}$ \\
\hline \multirow[t]{3}{*}{ (36) } & S. Hadar $(n=38)$ & - & - & - & - & $37(97.4)$ & $38(100)$ & $37(97.4)$ \\
\hline & S. Kentucky $(n=15)$ & - & $1(6.7)$ & $15(100)$ & - & $12(80)$ & $14(93.3)$ & - \\
\hline & S. Enteritidis $(n=5)$ & - & - & $5(100)$ & - & - & - & $5(100)$ \\
\hline \multirow[t]{3}{*}{ (37) } & S. Hadar $(n=47)$ & $0(0)$ & $0(0)$ & $0(0)$ & $0(0)$ & $46(97.9)$ & $46(97.9)$ & $44(93.6)$ \\
\hline & S. Typhimurium $(n=9)$ & $2(22.2)$ & $0(0)$ & $2(22.2)$ & $2(22.2)$ & $2(22.2)$ & $2(22.2)$ & $0(0)$ \\
\hline & S. Kentucky $(n=5)$ & $5(100)$ & $2(40)$ & $5(100)$ & $0(0)$ & $4(80)$ & $4(80)$ & $0(0)$ \\
\hline \multirow[t]{3}{*}{ (38) } & S. Anatum $(n=39)$ & $0(0)$ & $0(0)$ & $0(0)$ & $0(0)$ & $1(2.6)$ & $2(5.1)$ & $0(0)$ \\
\hline & S. Newport $(n=13)$ & $0(0)$ & $0(0)$ & $0(0)$ & $0(0)$ & $3(23)$ & $10(77)$ & $0(0)$ \\
\hline & S. Eastboume $(n=8)$ & $0(0)$ & $0(0)$ & $0(0)$ & $0(0)$ & $0(0)$ & $1(12.5)$ & $0(0)$ \\
\hline \multirow[t]{4}{*}{ (39) } & S. Typhimurium $(n=6)$ & $0(0)$ & $0(0)$ & $0(0)$ & 1(16.7) & 1(16.7) & $1(16.7)$ & $0(0)$ \\
\hline & S. Newport $(n=6)$ & $0(0)$ & $0(0)$ & $0(0)$ & $0(0)$ & $4(66.7)$ & $0(0)$ & $0(0)$ \\
\hline & S. Infantis $(n=5)$ & $0(0)$ & $0(0)$ & $0(0)$ & $0(0)$ & $0(0)$ & $0(0)$ & $0(0)$ \\
\hline & S. Haifa $(n=3)$ & $2(66.7)$ & $0(0)$ & $0(0)$ & $0(0)$ & $3(100)$ & $2(66.7)$ & $0(0)$ \\
\hline \multirow[t]{5}{*}{ (41) } & S. Dublin $(n=3)$ & $0(0)$ & $0(0)$ & $0(0)$ & $0(0)$ & $0(0)$ & $0(0)$ & $0(0)$ \\
\hline & S. Kentucky $(n=5)$ & $5(100)$ & $5(100)$ & $5(100)$ & $0(0)$ & $5(100)$ & $5(100)$ & $0(0)$ \\
\hline & S. Saintpaul $(=6)$ & $0(0)$ & $0(0)$ & $0(0)$ & $0(0)$ & 1(16.7) & $0(0)$ & $0(0)$ \\
\hline & S. Typhimurium $(n=7)$ & $0(0)$ & $0(0)$ & $0(0)$ & $0(0)$ & $0(0)$ & $0(0)$ & $0(0)$ \\
\hline & S. Virchow $(n=5)$ & $3(60)$ & $1(20)$ & $0(0)$ & $0(0)$ & $2(40)$ & $1(20)$ & $0(0)$ \\
\hline \multirow[t]{4}{*}{ (44) } & S. Saintpaul $(=20)$ & $9(45)$ & $0(0)$ & $0(0)$ & $10(50)$ & $18(90)$ & $4(20)$ & $5(25)$ \\
\hline & S. Typhimurium $(n=3)$ & $0(0)$ & $0(0)$ & $0(0)$ & $0(0)$ & $3(100)$ & $1(33.3)$ & $1(33.3)$ \\
\hline & S. Kentucky $(n=2)$ & $2(100)$ & $2(100)$ & $2(100)$ & $1(50)$ & $2(100)$ & $2(100)$ & 0 \\
\hline & S. Haifa $(n=1)$ & $0(0)$ & $0(0)$ & $0(0)$ & $0(0)$ & $1(100)$ & $1(100)$ & $1(100)$ \\
\hline
\end{tabular}

\section{Discussion}

Salmonellosis is one of the public health problems of humans and animals in both developed and developing countries (34). Animals are the main reservoirs of human Salmonellosis $(12,13)$ though vegetable foods contaminated by animal products and human excreta have been implicated as the automobile of human salmonellosis (14). Consumption of animal food from infected animals or from the contamination of carcasses (10) such as cattle, swine, and sheep (11) are the main sources of non-Typhoidal Salmonella and the leading cause of zoonotic foodborne diseases.

In this review, 6721 samples (cattle, pig, poultry, and eggs) were collected from 11 eligible studies to assess the prevalence of animal Salmonellosis in Ethiopia. A total of 564 Salmonella species were identified and $8.4 \%$ was found to be a pooled 
prevalence of salmonella species in animals in Ethiopia.

This pooled prevalence (8.4\%) was in line with studies carried out in Ethiopia (40,42, 43, and 45). Hence, there were studies in the same country which showed lower $(29,31,39,41,44$ and 46$)$ and higher $(30,31,33,36-38)$ prevalence with a range of $1.3 \%$ (29) to $23.7 \%$ (28). This was also in line with studies carried out in Nigeria (28), Burkinafaso (47) and Italy (48) but lower than studies from Vietnam (15), China, (21), Louisiana (23), Kenya (49), South Africa (50) and Uganda (51).

A total number of 354 serotypes were summarized from six studies and named into 29 serotypes of salmonella. Cumulatively, the following serotypes were ordered from the highest to the lowest starting from S. Hadar 74 (20.9\%), S. Saintpaul 55(15.5\%), S. Anatum 49 (13.8\%), S. Eastbourne 41 (11.6\%), S. Typhimurium 31 (8.8\%), S. Kentucky 25 (7.1\%), S. Newport 24 (6.8\%) and S. Enteritidis 9 (2.5\%). However; each of the serotypes had their own predomination in the different studies such as S. Hadar in two studies $(36,37)$, S. Anatum in one study (38), S. Typhimurium from dairy cattle (44), slaughtered sheep and goat (27), and in humans (52) in Addis Ababa, Ethiopia. Likewise, S. Typhimurium was reported as a predominant from chicken meat in Egypt (53) and retail meat in Turkey (24), poultry and poultry products in India (54), vegetables in Mexico (55), and China (56).

S. Typhimurium and S. Enteritidis are stated as the common NTS serotypes in Sub Saharan Africa that are associated with invasive infection in humans (57-59). The presence of such salmonella prevalence in cattle, poultry, pigs and other animal sources possibly considered as a potential sources of contamination in humans and may the main risk factors for the Salmonella outbreaks in humans $(60,61)$.

In spite of the fact that ceftriaxone (cephalosporin) and ciprofloxacin (quinolones) has not been used for the treatment of animal salmonellosis in Ethiopia. However; ceftriaxone resistance species of salmonella has reported in two studies in Ethiopia $(42,46)$ although the serotype level ceftriaxone resistance report was not found. Similarly, ciprofloxacin resistance of Salmonella was reported in species $(42,43)$ and serotype level in Ethiopia $(36,37,41$, and 44$)$. All of the isolates of S. Kentucky in four studies in Ethiopia showed resistance to ciprofloxacin $(36,37,41$, and 44$)$ though S. Kentucky was not demonstrated in other studies in Ethiopia $(29,38,39,62$, and 63).

Twelve serotypes having 204 isolates were found eligible to assess the antimicrobial resistance. Six serotypes showed multidrug resistance comprising 120 isolates. The predominant serotype that showed MDR (to three antibiotics) was S. Hadar 81 (67.5\%) (36, 37) followed by S. Kentucky 22(18.3\%) $(36,37,41,44)$, Table 5. 
Table 5

Multidrug-resistant (MDR) Serotypes of Salmonella isolates of animal sources

\begin{tabular}{|lllll|}
\hline Serotypes & Infected host & Resistant isolates & MDR pattern & Author \\
\hline S. Typhimurium & Pig & 2 & Amp, Cip, C, S, T & $(37)$ \\
\hline & Cattle & 1 & C, S, T & $(38)$ \\
\hline S. Kentucky & Poultry & 1 & S, T, F & $(44)$ \\
\hline & Pig & 2 & Amp, Gen, C, S, T & $(37)$ \\
\hline & Pig & 2 & Amp, Cip, S, T & $(37)$ \\
\hline & Cattle & 5 & Amp, Gen, Cip, S, T & $(41)$ \\
\hline Poultry & 1 & Amp, Gen, Cip, C, S, T & $(44)$ \\
\hline S. Saintpaul & Poultry & 1 & Amp, Gen, Cip, S, T & $(44)$ \\
\hline & Pig & 1 & Gen, Cip, S, T & $(36)$ \\
\hline Pig & 10 & Cip, S, T & $(36)$ \\
\hline S. Haifa & Poultry & 4 & Amp, C, S, T, F & $(44)$ \\
\hline poultry & 1 & Amp, C, S, F & $(44)$ \\
\hline S. Hadar & poultry & 4 & Amp, C, S & $44)$ \\
\hline S. Virchow & cattle & 2 & Amp, T, F & $(39)$ \\
\hline AMP Ampicillin, GEN Gentamycin, CIP Ciprofloxacin, C Chloramphenicol, S Streptomycin, T Tetracycline, F Nitrofurantoin \\
\hline
\end{tabular}

\section{Conclusions}

Eleven studies were found eligible to carry out a systematic review in animal salmonellosis in Ethiopia. Five of them were eligible to analyze the prevalence of Salmonella species and their antimicrobial resistance whereas the other six were eligible to assess the prevalence of Salmonella in serotype level. We selected eight commonly tested antimicrobials in species level (ampicillin, gentamycin, ciprofloxacin, chloramphenicol, streptomycin, tetracycline, nitrofurantoin, and ceftriaxone) whereas seven in serotype level (ampicillin, gentamycin, ciprofloxacin, chloramphenicol, streptomycin, tetracycline, and nitrofurantoin).

From the 11 studies, 6721 samples were collected and the sources of samples were pigs, cattle, poultry, and eggs. The overall number of positive isolates of Salmonella revealed from the 11 eligible studies were 564(8.4\%).

Twenty-nine Salmonella serotypes were extracted from the six eligible studies which comprised a total number of 354 serotypes. Of the total 354 , the contribution of each of the twenty-one serotypes had less than $2 \%$ whereas the other eight serotypes have a range from 74 (20) in S. Hadar to 9 (2.5\%) in S. Enteritidis. Salmonella enterica serovars Newport and Salmonella enterica serovars Typhimurium have multiple host ranges (Table 2). 
Of the total 147(6.1\%) Salmonella species summarized from the five eligible studies, 89 (60.5\%), 70 (47.6\%) and 64(43.5\%) isolates were found resistant for ampicillin, streptomycin, and tetracycline, respectively. Less resistant were observed in ciprofloxacin 10 (6.8\%), gentamicin 21 (12.9\%) and ceftriaxone 20 (13.6\%) (Fig. 2).

Twelve serotypes having 204 isolates were found eligible to assess the antimicrobial resistance. Six serotypes showed multidrug resistance comprising 120 isolates. The predominant serotype that showed MDR (to three antibiotics) was S. Hadar 81 (67.5\%) followed by S. Kentucky 22(18.3\%).

\section{Methods}

\section{Eligibility Criteria}

The eligibility criteria of this study included publication in English, cross-sectional study, samples of food animal origin, microbial isolation, identification, and antimicrobial sensitivity test methods, and the number of tested isolates and antimicrobial susceptibility testing.

\section{Literature search strategies}

Articles related to animals, human salmonellosis were searched in Google Scholar and PubMed. The terms used to search the articles were prevalence, epidemiology, incidence, Salmonella, distribution, antimicrobial resistance, animals, humans, and food. The search covered published articles up to December 30, 2019.

\section{Data extraction}

Author, location, study period, animal name, sample sources, isolation method, number of animals, number of Samples, Positive (\%)/sample, number of drugs, drug test. Serotypes were also extracted from some of the studies. The prevalence of non-typhoidal Salmonella was calculated by using the numbers of isolates as a nominator and the total samples as the denominator.

\section{Abbreviations}

ISO International Organizations for Standardization, PRISMA Preferred Reporting Items for Systematic Review and MetaAnalysis, MDR Multidrug-resistant, XLD Xylose lysine Deoxycholate, BGA Brilliant Green Agar

\section{Declarations}

Ethics approval and consent to participate: Not applicable

Consent for publication: Not applicable

Availability of data and material: All the data used to write this manuscript are available on hand and I can share up on call.

Competing interests: The author declare that I have no competing interests.

Funding: Not applicable

\section{Authors' contributions}

AGK was involved in data collection, analysis, drafting the review manuscript and critically reviewing the manuscript.

Acknowledgements: I would like to thank those who support me during data extraction and reviewing the manuscript before submitting to the journal. 


\section{References}

1. Wray, C. and A. Wray, Salmonella in domestic animals2000: Cabi.

2. Hald, T., Pires, Sara M, de Knegt, Leonardo, Development of a Salmonella source-attribution model for evaluating targets in the turkey meat production. EFSA Supporting Publications, 2012. 9(4): p. 259E.

3. Grimont PAD and Weill FX. Antigenic formulae of the Salmonella serovars. WHO collaborating center for reference and research on Salmonella, 2007. 9: p. 1-166.

4. Maskell D. Salmonella infections: clinical, immunological and molecular aspects. Vol. 9. 2006: Cambridge University Press.

5. Mughini-Gras, L., et al., Risk factors for human salmonellosis originating from pigs, cattle, broiler chickens and egglaying hens: a combined case-control and source attribution analysis. PloS one, 2014. 9(2).

6. Hald, T. and J. Lund, Development of a user-friendly interface version of the Salmonella source-attribution model. EFSA Supporting Publications, 2012. 9(7): p. 318E.

7. Ao, T.T., et al., Global burden of invasive nontyphoidal Salmonella disease, 2010. Emerging infectious diseases, 2015. 21(6): p. 941.

8. Majowicz, S.E., et al., The global burden of nontyphoidal Salmonella gastroenteritis. Clinical infectious diseases, 2010. 50(6): p. 882-889.

9. Arroyo, G. and J. Arroyo, Detection of Salmonella serotypes in edible organ meats from markets in Madrid, Spain. Food Microbiology, 1995. 12: p. 13-20.

10. Acha, P.N. and B. Szyfres, Zoonoses and communicable diseases common to man and animals. Vol. 580. 2003: Pan American Health Org.

11. Hugas, M. and P. Beloeil, Controlling Salmonella along the food chain in the European Union-progress over the last ten years. Euro surveillance, 2014. 19(19): p. 20804.

12. NABBUT, N.H. and H.M. AL-NAKHLI, Incidence of salmonellae in lymph nodes, spleens, and feces of sheep and goats slaughtered in the Riyadh public abattoir. Journal of food protection, 1982. 45(14): p. 1314-1317.

13. Smeltzer, T., R. Thomas, and G. Collins, The role of equipment having accidental or indirect contact with the carcass in the spread of Salmonella in an abattoir. Australian veterinary journal, 1980. 56(1): p. 14-17.

14. Mannion, C., et al., The role of transport, lairage and slaughter processes in the dissemination of Salmonella spp. in pigs in Ireland. Food research international, 2012. 45(2): p. 871-879.

15. Huong, L.Q., et al., Prevalence of Salmonella in retail chicken meat in Hanoi, Vietnam. Annals of the New York Academy of Sciences, 2006. 1081(1): p. 257-261.

16. Sodagari, H.R., Z. Mashak, and A. Ghadimianazar, Prevalence and antimicrobial resistance of Salmonella serotypes isolated from retail chicken meat and giblets in Iran. The Journal of Infection in Developing Countries, 2015. 9(05): p. 463-469.

17. Centers for Disease Control and Prevention (CDC). Antibiotic Resistance Threats in the United States. 2013. Available online: https://www.cdc.gov/drugresistance/pdf/ar-threats-2013-508.

18. Tauxe, R.V.; Widdowson, M.-A.; Roy, S.L.; Jones, J.L.; Griffin, P.M. Foodborne illness acquired in the United States-Major pathogens. Emerg. Infect. Dis. 2011, 17, 7-15.

19. Alali, W.Q., et al., Prevalence of Salmonella on retail chicken meat in the Russian Federation. Journal of food protection, 2012. 75(8): p. 1469-1473.

20. Hyeon, J.-Y., et al., Prevalence, antibiotic resistance, and molecular characterization of Salmonella serovars in retail meat products. Journal of food protection, 2011. 74(1): p. 161-166.

21. Yang, B., et al., Prevalence of Salmonella on raw poultry at retail markets in China. Journal of food protection, 2011. 74(10): p. 1724-1728.

Page 13/17 
22. Wong, T.L., et al., Salmonella in uncooked retail meats in New Zealand. Journal of food protection, 2007. 70(6): p. 13601365.

23. Lestari, S.I., et al., Prevalence and antimicrobial resistance of Salmonella serovars in conventional and organic chickens from Louisiana retail stores. Journal of food protection, 2009. 72(6): p. 1165-1172.

24. Arslan, S. and A. Eyi, Occurrence and antimicrobial resistance profiles of Salmonella species in retail meat products. Journal of food protection, 2010. 73(9): p. 1613-1617.

25. Donado-Godoy, P., et al., Prevalence of Salmonella on retail broiler chicken meat carcasses in Colombia. Journal of food protection, 2012. 75(6): p. 1134-1138.

26. Gharieb, R.M., Y.H. Tartor, and M.H. Khedr, Non-Typhoidal Salmonella in poultry meat and diarrhoeic patients: prevalence, antibiogram, virulotyping, molecular detection and sequencing of class I integrons in multidrug-resistant strains. Gut pathogens, 2015. 7(1): p. 34.

27. Kagambèga, A., et al., Prevalence and characterization of Salmonella enterica from the feces of cattle, poultry, swine and hedgehogs in Burkina Faso and their comparison to human Salmonella isolates. BMC microbiology, 2013. 13(1): p. 253.

28. Tafida, S., et al., Occurrence of Salmonella in retail beef and related meat products in Zaria, Nigeria. Food Control, 2013. 32(1): p. 119-124.

29. Molla, W., et al., Occurrence and antimicrobial resistance of Salmonella serovars in apparently healthy slaughtered sheep and goats of central Ethiopia. Tropical animal health and production, 2006. 38(6): p. 455-462.

30. Dawit Nguse, A.K., Endale Balcha, Prevalence of Salmonella in Eggs Collected from Local Markets and Poultry Farms in Mekelle, Ethiopia. European Journal of Biological Sciences 2015. 7: p. 4.

31. Kokeb Korea, B.A., Kassa Demissiec, Kassaye Aragawb, Characterization of Salmonella isolated from apparently healthy slaughtered cattle and retail beef in Hawassa, southern Ethiopia. Preventive Veterinary Medicine, 2017. 147: p. 11-16.

32. EJETA, B.M., D. ALEMAYEHU1, and A. MUCKLE, Salmonella serotypes isolated from minced meat beef, mutton, and pork in Addis Ababa, Ethiopia. Revue Méd. Vét., 2004. 155(11): p. 5.

33. Reta Duguma Abdi, F.M., Ashenafi Feyisa Beyi, Takele Beyene, Hika Waktole, Bedasso Mammo, Dinka Ayana, and Fufa Abunna, Determination of the sources and antimicrobial resistance patterns of Salmonella isolated from the poultry industry in Southern Ethiopia. BMC Infectious Diseases 2017. 17.

34. H, K., WHO, and OIE Collaboration in Food safety and Zoonosis, Seminar, 2013, WHO/Europe: Belgrade, Servia.

35. Moher D, L.A., Tetzlaff J, Altman DG. The PRISMA (Preferred Reporting Items for Systematic review and Meta-Analysis) Group (2009). Preferred Reporting Items for Systematic Review s and Meta-Analyses: The PRISMA Statement. PLoS Med 2009. 6(6).

36. Molla, A.B., et al., Multidrug Resistance and Distribution of Salmonella Serovars in Slaughtered Pigs. Journal of Veterinary Medicine in 2006. 53: p. 6.

37. Aragaw K, M.B., Muckle A, Cole L, Wilkie E, Poppe C, Kleer J, Hildebrandt G, The characterization of Salmonella serovars isolated from apparently healthy slaughtered pigs at Addis Ababa abattoir, Ethiopia. Preventive Veterinary Medicine 2007. 82: p. 252-261.

38. Sibhat B, M.Z.B., Zerihun A, Muckle A, Cole L, Boerlin P, Wilkie E, Perets A, Mistry K, and Gebreyes WA, Salmonella Serovars and Antimicrobial Resistance Profiles in Beef Cattle, Slaughterhouse Personnel and Slaughterhouse Environment in EthiopiaZoonoses and Public Health, 2011. 58: p. 102-109.

39. Alemu, S. and B.M. Zewde, Prevalence and antimicrobial resistance profiles of Salmonella enterica serovars isolated from slaughtered cattle in Bahir Dar, Ethiopia. Tropical animal health and production, 2012. 44(3): p. 595-600.

40. Zelalem Addis, N.K., Zufan Sisay, Haile Alemayehu, Alehegne Yirsaw and Tesfu Kassa, Prevalence and antimicrobial resistance of Salmonella isolated from lactating cows and in contact humans in dairy farms of Addis Ababa: a crosssectional study. BMC Infectious Diseases 2011. 11: p. 111. 
41. Eguale Tadesse, E.E., Gebreyes Wondwossen A, Asrat Daniel, Alemayehu Haile, Medhin Girmay, Johnson Roger P and Gunn John S, Fecal prevalence, serotype distribution and antimicrobial resistance of Salmonellae in dairy cattle in central Ethiopia. BMC microbiology, 2016. 16(1): p. 20.

42. Wabeto, W., Y. Abraham, and A.A. Anjulo, Detection and identification of antimicrobial-resistant Salmonella in raw beef at Wolaita Sodo municipal abattoir, Southern Ethiopia. Journal of Health, Population and Nutrition, 2017. 36(1): p. 52.

43. Beyan Ahmed Mustafa, E.Z.G., Carriage and antimicrobial resistance of non-typhoidal Salmonella in cattle slaughtered in Ambo municipality abattoir, West Shewa zone, Oromia, Ethiopia- a point prevalence survey. Ethiopian Veterinary Journal, 2018. 22(2): p. 94-109.

44. Eguale, T., Non-typhoidal Salmonella serovars in poultry farms in central Ethiopia: prevalence and antimicrobial resistance. BMC Veterinary Research, 2018. 14.

45. Samson Takele, K.W., Mulatu Gashaw, Haimanot Tassew, Moti Yohannes, and Alemseged Abdissa, Prevalence and drug susceptibility pattern of Salmonella isolates from apparently healthy slaughter cattle and personnel working at the Jimma municipal abattoir, south-West Ethiopia. Tropical Diseases, Travel Medicine and Vaccines, 2018. 4.

46. Diriba Taddese, T.T., Benti Deresa, Matios lakow, Abebe Olani, and Eshetu Shumi, Antibiograms and risk factors of Salmonella isolates from laying hens and eggs in Jimma Town, South-Western Ethiopia. BMC Res Notes, 2019. 12: $p$. 472.

47. Kagambe GA, Haukka K, Sitonen A, Traore AS, and Barro N. Prevalence of Salmonella enterica and the Hygienic Indicator Escherichia coli in Raw Meat at Markets in Ouagadougou, Burkina Faso. Journal of Food Protection 2011, 74 (9): 15471551.

48. Busani L, Cigliano A, Taioli E, Caligiuri V, Chiavacci L, DI BELLA Prevalence of Salmonella enterica and Listeria monocytogenes Contamination in Foods of Animal Origin in Italy. Journal of Food Protection 2005, 68 (8):1729-1733.

49. Langata LM, Maingi JM, Musonye HA, Kiiru J and Nyamache AK. Antimicrobial resistance genes in Salmonella and Escherichia coli isolates from chicken droppings in Nairobi, Kenya. BMC Res Notes 2019, 12:22.

50. Magwedere K, Rauff D, Klerk GD, Keddy KH, and Dziva F. Incidence of Nontyphoidal Salmonella in Food-Producing Animals, Animal Feed, and the Associated Environment in South Africa, 2012-2014. Clinical Infectious Diseases 2015, 61:283.

51. Odoch T, Wasteson Y, Abée-Lund TL, Muwonge A, Kankya C, Nyakarahuka L, et al. Prevalence, antimicrobial susceptibility and risk factors associated with non-typhoidal Salmonella on Ugandan layer hen farms. BMC Veterinary Research (2017) 13:365.

52. Eguale T, Gebreyes WA, Asrat D, Alemayehu H, Gunn JS and Engidawork E. Non-typhoidal Salmonella serotypes, antimicrobial resistance and co-infection with parasites among patients with diarrhea and other gastrointestinal complaints in Addis Ababa, Ethiopia. BMC Infectious Diseases (2015) 15:497.

53. Gharieb RM, Tartor YH and Khedr MH. Non-Typhoidal Salmonella in poultry meat and diarrhoeic patients: prevalence, antibiogram, virulotyping, molecular detection and sequencing of class I integrons in multidrug resistant strains. Gut Pathog (2015) 7:34.

54. Saravanan S, Purushothaman V, Ramasamy T, Murthy GK, Sukumar K, and Srinivasan P, et al. Molecular Epidemiology of Nontyphoidal Salmonella in Poultry and Poultry Products in India: Implications for Human Health. Indian J Microbiol, 2015, 55(3):319-326.

55. Quiroz-Santiago C, Rodas-sua' Rez OR, Zquez CR, Ferna' Ndez FJ, ONES-RAMI'REZ El, and VA' ZQUEZ-SALINAS C. Prevalence of Salmonella in Vegetables from Mexico. Journal of Food Protection 2009, 72 (6): 1279-1282

56. Liang Z, Ke B, Deng X, Liang J, Ran L , Lu L, et al. Serotypes, seasonal trends, and antibiotic resistance of non-typhoidal Salmonella from human patients in Guangdong Province, China, 2009-2012

57. Kariuki S, Revathi G, Kariuki N, Kiiru J, Mwituria J and Hart CA. Characterization of community-acquired non-typhoidal Salmonella from bacteremia and diarrhoeal infections in children admitted to hospital in Nairobi, Kenya. BMC Microbiology 2006, 6:101. 
58. Tabu C, Breiman RF, Ochieng B, Aura B, Cosmas L, Audi A, et al. Differing Burden and Epidemiology of Non-Typhi Salmonella Bacteremia in Rural and Urban Kenya, 2006- 2009. PLoS ONE 32012, 7(2): e31237. doi:10.137.

59. Gordon MA, Graham SM, Walsh AL, Wilson L, Phiri A, Molyneux E. Epidemics of Invasive Salmonella enterica Serovar Enteritidis and S. enterica Serovar Typhimurium Infection Associated with Multidrug Resistance among Adults and Children in Malawi. Clinical Infectious Diseases 2008; 46:963-9

60. Antunes P, Mourao J, Campos J, Peixe L. Salmonellosis: the role of poultry meat. Clin Microbiol Infect. 2016; 22(2):11021.

61. Hugas M, Beloeil P. Controlling Salmonella along the food chain in the European Union - progress over the last ten years. Euro Surveill. 2014;19(19)

62. Alemayehu D, Molla B, Muckle A. Prevalence and antimicrobial resistance pattern of Salmonella isolates from apparently healthy slaughtered cattle in Ethiopia. Trop Anim Health Prod. 2003; 35:309-19.

63. Molla B, Salah W, Alemayehu D, Mohammed A. Antimicrobial resistance pattern of Salmonella serotypes isolated from apparently healthy slaughtered camels (Camelus dromedarius) in Eastern Ethiopia. Berl Münch Tierärztl Wschr. 2004; 117:39-45.

\section{Figures}
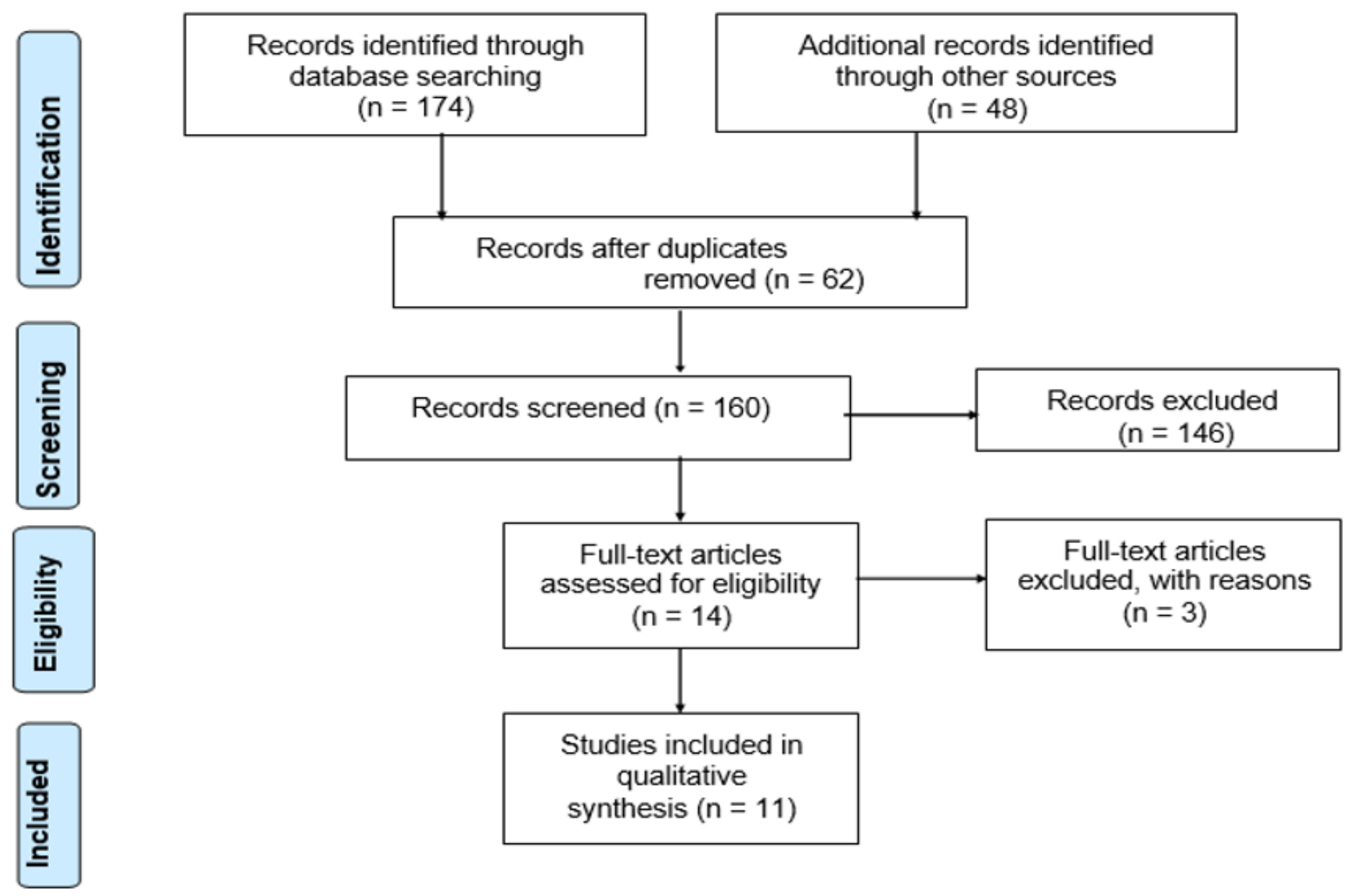

Figure 1

A flow diagram of the selection of the eligible studies 


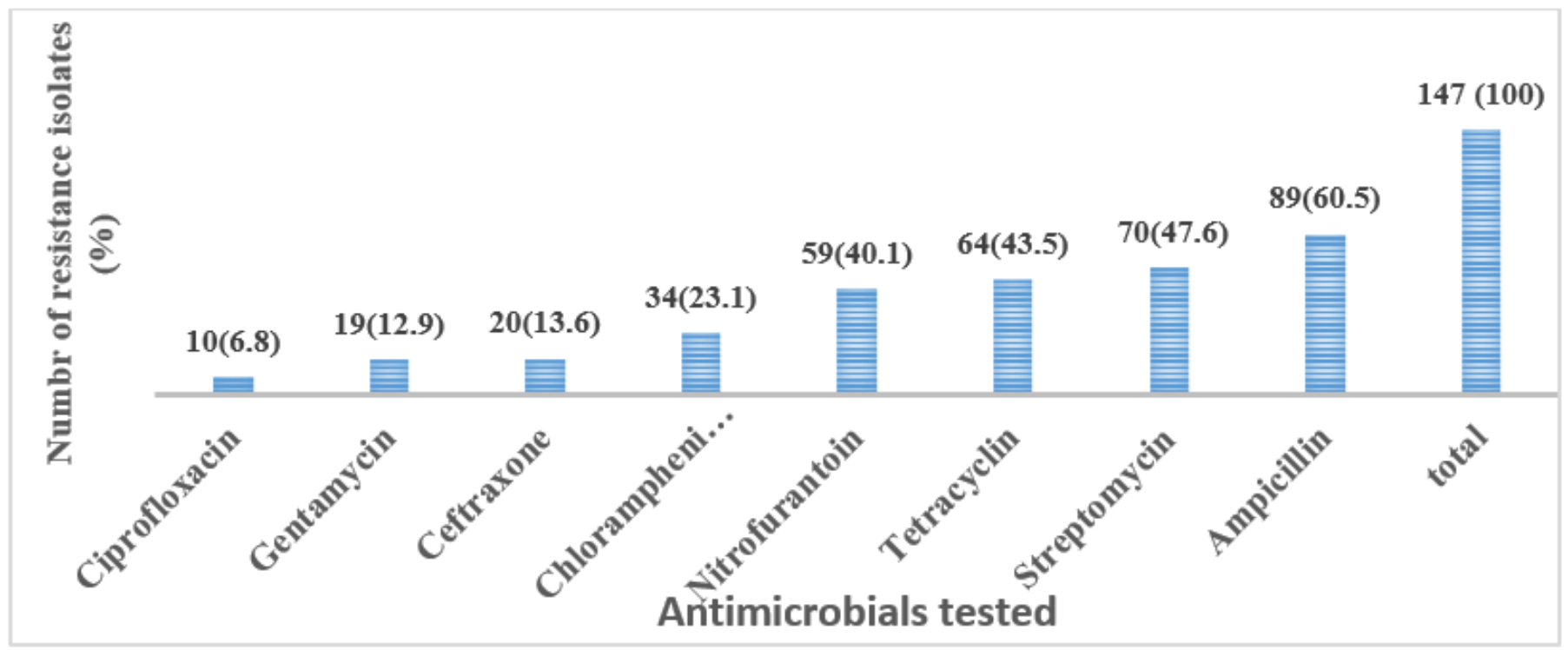

Figure 2

Pooled drug-resistant profile of animal salmonellosis 